\title{
Analisis Sistem Tenaga dan Redesign Tower Crane Potain MD 900
}

\author{
Intan Kumala Bestari dan I Nyoman Sutantra \\ Jurusan Teknik Mesin, Fakultas Teknologi Industri, Institut Teknologi Sepuluh Nopember (ITS) \\ e-mail:tantra@me.its.ac.id
}

\begin{abstract}
Abstrak- Tower crane adalah alat yang digunakan untuk mengangkut material secara vertikal dan horizontal ke suatu tempat yang tinggi pada ruang gerak yang terbatas. Prinsip yang digunakan dalam menentukan beban yang mampu diangkut oleh tower crane adalah berdasarkan prinsip momen. Semakin berat beban yang harus diangkut, maka radius operasi yang dicapai menjadi semakin kecil. Berdasarkan studi lapangan yang telah dilakukan di PT. Dok dan Perkapalan Surabaya tower crane dengan merek Potain MD 900 berkapasitas angkat 50 ton pada jarak lengan 21,10 meter hanya mampu mengangkat beban sebesar 40 ton. Sedangkan pada spesifikasi tower crane Potain MD 900 pada jarak lengan yang sama yaitu 21,10 meter beban yang dapat diangkut sebesar 50 ton. Dalam menentukan daya motor pada tower crane selain gaya berat (gaya statis) dari beban angkat juga terjadi percepatan (gaya dinamis) yang perlu diperhitungkan. Oleh karena perbedaan nilai dari daya motor terhadap kapasitas angkat ini maka pada tugas akhir ini akan dilakukan analisis pada perhitungan statis maupun dinamis dalam menentukan daya motor pada tower crane. Selain itu perlu juga dilakukan analisis terhadap nilai rasio gearbox yang terdapat pada tower crane saat ini, sehinga dapat dilakukan redesign agar mendapat nilai rasio gearbox yang lebih kecil dari saat ini dan harga gearbox akan lebih murah. Pada tugas akhir ini terdapat 2 tahapan, yaitu tahap analisis pada perhitungan dinamis maupun statis dalam menentukan daya motor dan rasi o gearbox yang dibutuhkan dengan kondisi tower crane saat ini. Kemudian setelah analisis dilakukan redesign pada komponen hoisting yaitu tali baja, pulley dan drum untuk meningkatkan kemampuan angkat tower crane dan juga memperkecil nilai rasio gearbox. Hasil perhitungan daya motor dengan kapasitas angkat maksimum sebesar 50 ton pada perhitungan statis didapatkan daya sebesar $88 \mathrm{~kW}$ sedangkan pada perhitungan dinamis didapatkan daya sebesar $110 \mathrm{~kW}$. Pada desain lama dengan rope reeving 2/1 dan kapasitas 40 ton, dengan perhitungan dinamis didapat daya motor $88 \mathrm{~kW}$ dan rasio gearbox sebesar 76,76 sedangkan pada hasil redesign dengan rope reeving $8 / 1$ dan kapasitas 50 ton didapat daya motor $110 \mathrm{~kW}$ dan rasio gearbox sebesar 10,5.
\end{abstract}

Kata Kunci-daya motor, putaran drum dan rasio gearbox.

\section{PENDAHULUAN}

$\mathrm{D}$ ALAM penyelesaian suatu proyek konstruksi ataupun pada industri galangan kapal biasanya digunakan crane sebagai alat bantu untuk mengangkat, mengangkut dan memindahkan suatu material maupun muatan. Salah satu perusahaan yang bergerak pada bidang perbaikan kapal adalah PT Dok dan Perkapalan Surabaya (DPS). Terdapat 24 crane di PT DPS yang dapat mengangkat sampai dengan 300 ton [1].
Prinsip yang digunakan dalam menentukan beban yang mampu diangkut oleh tower crane adalah berdasarkan prinsip momen. Panjang lengan tower crane dan kemampuan angkut muatan merupakan perbandingan yang bersifat linier. Semakin berat beban yang harus diangkut, maka radius operasi yang dicapai menjadi semakin kecil [2]. Di PT DPS terdapat 2 tower crane dengan merek Potain MD 900. Tower crane tersebut memiliki kapasitas angkat sebesar 32 ton dan 50 ton, untuk tower crane dengan kapasitas angkat 50 ton terdapat rope reeving sebesar $2 / 1$. Pada saat pengujian beban angkat didapatkan hasil bahwa tower crane dengan kapasitas angkat 50 ton pada jarak lengan 21,10 meter hanya mampu mengangkat beban sebesar 40 ton. Sedangkan pada spesifikasi tower crane Potain MD 900 pada jarak lengan yang sama yaitu 21,10 meter seharusnya beban yang dapat diangkut sebesar 50 ton. Pada mekanisme pengangkatan tower crane digunakan motor dengan daya sebesar $88 \mathrm{~kW}$. Dalam menentukan daya motor pada tower crane selain gaya berat (gaya statis) dari beban angkat juga terjadi percepatan (gaya dinamis) yang perlu diperhitungkan. Oleh karena perbedaan nilai dari daya motor terhadap kapasitas angkat ini perlu dilakukan perhitungan baik secara statis maupun dinamis. Pada tower crane untuk mereduksi putaran dari motor yang digunakan untuk memutar drum maka diperlukan adanya gearbox. Pemilihan gearbox dapat ditentukan berdasarkan nilai rasio gearbox, semakin besar nilai rasio gearbox maka akan semakin mahal harga gearbox tersebut.

Berdasarkan beberapa hal diatas maka pada tugas akhir ini penulis akan melakukan analisis sistem tenaga baik dengan perhitungan dinamis maupun statis, selanjutnya dapat menentukan hal apa saja yang perlu dilakukan redesign pada tower crane merek Potain MD 900, buatan Perancis tahun 1989 ini agar kapasitas angkatnya naik menjadi 50 ton. Selain itu akan dilakukan analisis juga rasio gearbox dengan rope reeving yang digunakan pada tower crane saat ini sehingga dapat diketahui dengan nilai rasio yang didapat perlu atau tidak dilakukan redesign agar mendapatkan rasio gearbox yang lebih kecil.

\section{URAIAN PENELITIAN}

Dalam penelitian ini akan dianalisis sistem tenaga pada tower crane Potain MD 900 yang terdapat pada PT DPS saat ini, kemudian akan dilakukan redesign untuk meningkatkan kemampuan angkat tower crane dan memperkecil rasio 


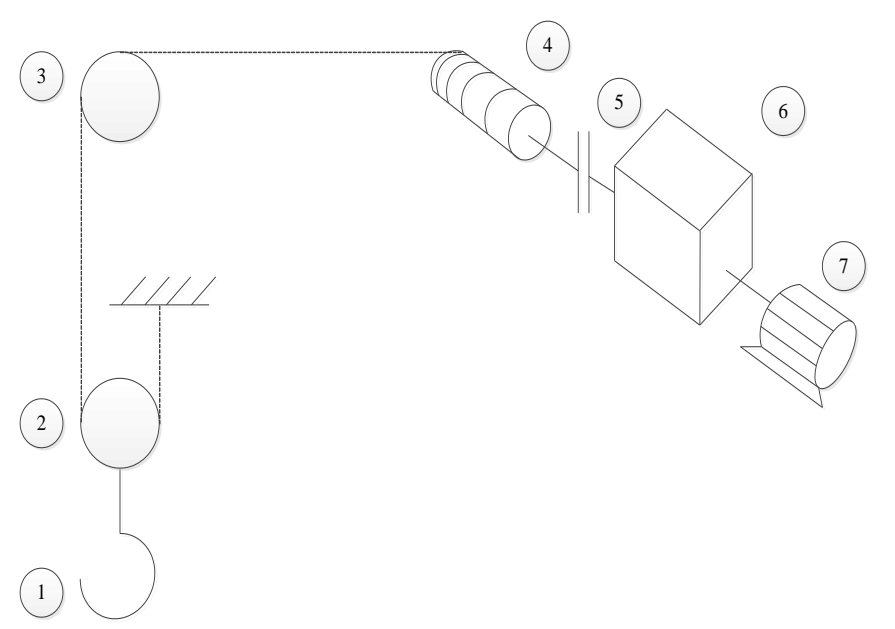

Gambar 1. Skema Mekanisme Pengangkat Tower Crane Potain MD 900.

gearbox. Penelitian ini dimulai dengan melakukan observasi di PT Dok dan Perkapalan Surabaya. Dari observasi ini didapatkan skema mekanisme pengangkat tower crane yang ada saat ini, seperti yang ditunjukkan pada gambar 1 :

Keterangan gambar:

1. Hook

2. Hook block pulley

3. Pulley

4. Drum

5. Kopling

6. Gearbox

7. Motor

Dari skema mekanisme diatas kemudian dilakukan analis is gaya tegang tali berdasarkan perhitungan statis dan dinamis untuk menentukan nilai daya motor. Pada perhitungan statis, gaya yang diperhitungkan adalah gaya berat beban angkat tower crane, sehingga besarnya nilai gaya tegang tali (T) dapat dicari menggunakan persamaan berikut [3]:

$$
T=\frac{m_{\text {beban }} \times g}{r}
$$

dimana,

$$
\begin{aligned}
& m_{\text {beban }}=\text { mass a beban angkat maksimum pada tower crane } \\
& \mathrm{g} \quad=\text { percepatan gravitasi }\left(\mathrm{m} / \mathrm{s}^{2}\right) \\
& \mathrm{r}
\end{aligned}
$$

Sedangkan pada perhitungan dinamis selain gaya berat beban angkat tower crane, juga diperhitungkan berat hook block pulley, besarnya nilai SWL yaitu 1.25 , gaya angkat dan gaya ayun, sehingga gaya tegang tali (T) dapat dicari menggunakan persamaan berikut [3]:

$$
T=\frac{W_{b}+F_{i}+F_{n}}{r}
$$

dimana,

$W_{b}=$ berat beban $\quad(\mathrm{N})$

$F_{i}=$ gaya angkat $\quad(\mathrm{N})$

$F_{n}=$ gaya ayun $\quad(\mathrm{N})$

Besarnya gaya angkat dapat dicari menggunakan persamaan berikut :

$$
F_{i}=\left(\left(m_{\text {beban }} \times 1.25\right)+m_{\text {hook }}\right) \times a
$$

Sedangkan untuk mencari percepatan pada saat pengangkatan dan penurunan benda [3]:

dimana,

$$
V_{t}=V_{0}+(a x t)
$$

$\mathrm{V}_{\mathrm{t}}=$ kecepatan angkat $(\mathrm{m} / \mathrm{s})$

$\mathrm{V}_{\mathrm{o}}=$ kecepatan awal $(\mathrm{m} / \mathrm{s})$

$\mathrm{a}=\operatorname{percepatan}\left(\mathrm{m} / \mathrm{s}^{2}\right)$

$\mathrm{t}=$ waktu yang dibutuhkan untuk mencapai kecepatan konstan (s)

Untuk gaya ayun dapat dicari menggunakan persamaan berikut :

$$
F_{n}=\left(\left(m_{\text {beban }} \times 1.25\right)+m_{\text {hook }}\right) \times a_{n}
$$

Nilai dari percepatan normal $\left(a_{n}\right)$ dapat dicari dengan rumus sebagaiberikut [3]:

$$
a_{n}=\frac{v^{2}}{R}
$$

dimana,

$\mathrm{V}=$ kecepatan angkat $(\mathrm{m} / \mathrm{s})$

$\mathrm{R}=$ panjang tali ketika beban angkat mengalami gaya ayun (m)

Sedangkan nilai $R$ merupakan tinggi angkat muatan dikurangi dengan jarak ketika beban angkat, sesaat mengalami kecepatan konstan yang besarnya adalah sebagai berikut [3]:

$$
\Delta h=V_{0} \cdot t-\frac{1}{2} \cdot a \cdot t^{2}
$$

dimana

$\mathrm{V}_{0}=$ kecepatan angkat awal $(\mathrm{m} / \mathrm{s})$

$\mathrm{t}=$ waktu yang dibutuhkan untuk mencapai kecepatan konstan (s)

$\mathrm{a}=\operatorname{percepatan}\left(\mathrm{m} / \mathrm{s}^{2}\right)$

Setelah menghitung gaya tegang tali dengan perhitungan statis dan dinamis kemudian menentukan nilai daya motor dengan menggunakan persamaan berikut [3] :

$$
P=\frac{T \times V}{1000 \times \eta}
$$

dimana,

$\mathrm{T}$ = gaya tegang tali $(\mathrm{N})$

$\mathrm{V}=$ kecepatan linier sling $(\mathrm{m} / \mathrm{s})$

Kemudian dengan perhitungan statis dan dinamis dilakukan perhitungan rasio gerabox dengan persamaan sebagaiberikut [4]:

$$
i=\frac{n_{m}}{n_{\text {drum }}}
$$

dimana,

$\mathrm{n}_{\mathrm{m}} \quad=$ putaran motor $(\mathrm{rpm})$

$\mathrm{n}_{\text {drum }}=$ putaran drum $(\mathrm{rpm})$

Setelah didapatkan nilai rasio gearbox dan daya motor, selanjutnya dilakukan analis is kemampuan angkat tower crane pada perhitungan statis dan dinamis. Kemudian dari analisis tersebut dilakukan redesign pada komponen hoisting yakni : tali baja, pulley, drum, gearbox dan motor dengan rope reeving 8 . Berikut adalah skema mekanisme pengangkat tower crane hasil redesign: 


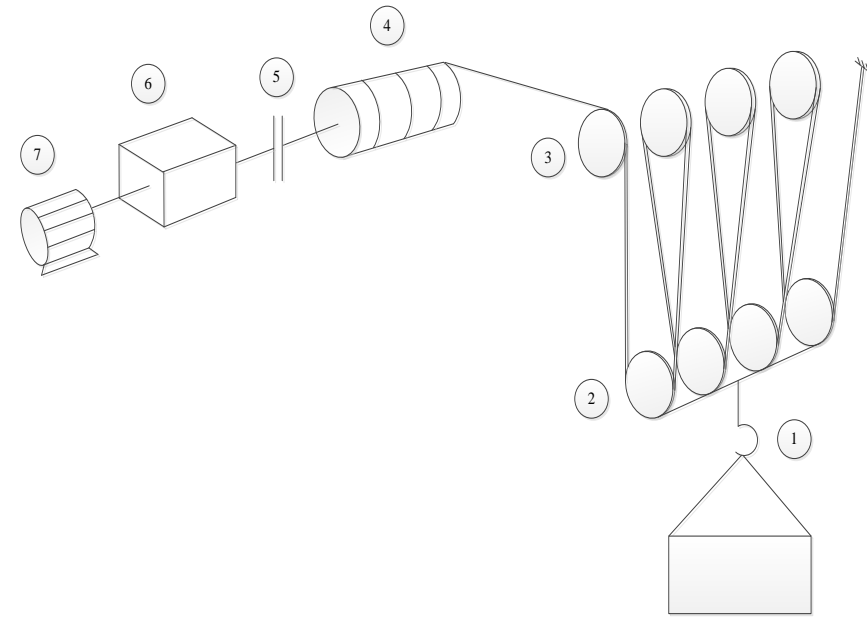

Gambar 2. Skema Mekanisme Pengangkat Tower Crane Hasil Redesign. Keterangan gambar 2 :

1. Hook

2. Hook block pulley

3. Pulley

4. Drum

5. Kopling

6. Gearbox

7. motor

Dari skema redesign diatas kemudian dilakukan pemilihan diameter tali berdasarkan gaya tegang tali pada katalog wire rope. Setelah didapatkan nilai diameter tali kemudian dilakukan perhitungan untuk mendapatkan nilai diameter pulley dengan persamaan sebagaiberikut [5]:

$$
D \geq e_{1} \cdot e_{2} \cdot d
$$

dimana,

$\mathrm{D}=$ diameter pulley pada dasar alurnya (mm)

$\mathrm{d}=$ diameter tali baja $(\mathrm{mm})$

$\mathrm{e}_{1}=$ Faktor yang tergantung pada tipe alat pengangkat dan kondisi operasinya

$\mathrm{e}_{2}=$ Faktor yang tergantung pada konstruksi tali

Tabel 2.

Harga Minimum Faktor K dan e $e_{1}$ yang Diizinkan

\begin{tabular}{|c|c|c|c|c|}
\hline TIPE ALATPENGANGKAT & $\begin{array}{l}\text { Digerak } \\
\text { kan } \\
\text { oleh }\end{array}$ & $\begin{array}{l}\text { Kondisi } \\
\text { pengoperasian }\end{array}$ & $\begin{array}{l}\text { Faktor } \\
\mathrm{K}\end{array}$ & $\begin{array}{l}\text { Faktor } \\
\text { el }\end{array}$ \\
\hline 1. Lokomotif caterpillar-mounted, traktor, dan & Tangan & Ringan & 4 & 16 \\
\hline truk yang mempunyai crane pillar (termasuk & Daya & Ringan & 5 & 16 \\
\hline excavator) yang diopersikan sebagai crane & Daya & Medium & 5,5 & 18 \\
\hline dan pengangkat mekanik pada daerah & Daya & Berat dan sangat berat & 6 & 20 \\
\hline konstruksi dan pekerjaan berkala & Tangan & Ringan & 4,5 & 18 \\
\hline $\begin{array}{l}\text { 2. Semua tipe lain dari crane dan pengangkat } \\
\text { mekanis }\end{array}$ & $\begin{array}{l}\text { Daya } \\
\text { Daya }\end{array}$ & $\begin{array}{l}\text { Ringan } \\
\text { Medium }\end{array}$ & $\begin{array}{l}5 \\
5,5\end{array}$ & $\begin{array}{l}20 \\
25\end{array}$ \\
\hline $\begin{array}{l}\text { 3. Derek yang dioperasikan dengan tangan, } \\
\text { dengan kapasitas beban terangkat diatas } 1 \\
\text { ton yang digandeng pada berbagai peralatan } \\
\text { otomotif (mobil, truk, dan sebagainya) }\end{array}$ & $\begin{array}{l}- \\
- \\
-\end{array}$ & $\begin{array}{l}\text { Berat dan sangat berat } \\
- \\
- \\
-\end{array}$ & $\begin{array}{l}6 \\
4 \\
5,5 \\
5\end{array}$ & $\begin{array}{l}30 \\
12 \\
20 \\
20\end{array}$ \\
\hline 4. Pengangkat dengan troli & & - & 5 & 30 \\
\hline $\begin{array}{l}\text { 5. Penjepit mekanis (kecuali untuk puli pada } \\
\text { grabs) untukpengangkat mekanis pada no } 1\end{array}$ & & & & \\
\hline 6. Idem untuk pengangkat mekanik pada no 2 & & & & \\
\hline
\end{tabular}

Tabel 1.

Harga Faktor $\mathrm{e}_{2}$ yang Tergantung pada Konstruksi Tali

\begin{tabular}{|c|c|}
\hline Konstruksi Tali & Faktor $\mathrm{e}_{2}$ \\
\hline \multicolumn{2}{|c|}{ Biasanya $6 \times 19=114+1$ poros : } \\
\hline Posisi berpotongan & 1,00 \\
\hline Posisi sejajar & 0,90 \\
\hline \multicolumn{2}{|c|}{ Compound $6 \times 19=114+1$ poros } \\
\hline \multicolumn{2}{|l|}{ a) Warrington } \\
\hline Posisi berpotongan & 0,90 \\
\hline Posisi sejajar & 0,85 \\
\hline \multicolumn{2}{|l|}{ b) Seale } \\
\hline Posisi berpotongan & 0,95 \\
\hline Posisi sejajar & 0,85 \\
\hline \multicolumn{2}{|c|}{ Biasanya $6 \times 37=222+1$ poros: } \\
\hline Posisi berpotongan & 1,00 \\
\hline Posisi sejajar & 0,90 \\
\hline
\end{tabular}

Nilai e 2 didapatkan dari tabel 1 sedangkan nilai $e_{1}$ didapatkan dari tabel 2.

Setelah didapatkan nilai diameter pulley kemudian dilakukan perhitungan untuk mencari nilai diameter drum dengan persamaan sebagai berikut :

$$
D_{\text {drum }}=20 \times d_{\text {tali }}
$$

Selain diameter drum juga dilakukan perhitungan diameter flange dengan persamaan sebagaj gerikut :

dimana,

$$
D_{2}=D_{\text {drum }}+2(z+1) d
$$

$\mathrm{D}_{2} \quad=$ diameter drum flange $(\mathrm{mm})$

$\mathrm{D}_{\text {drum }}=$ diameter drum $(\mathrm{mm})$

$\mathrm{z} \quad=$ jumlah tingkat tali pada drum

$\mathrm{d} \quad=$ diameter tali baja $(\mathrm{mm})$

Sedangkan untuk menentukan lebar drum dapat ditentukan dari katalog drum berdasarkan nilai diameter tali. Kemudian dilakukan perhitungan untuk menentukan putaran diameter dengan persamaan sebagai berikut [5] :

dimana,

$$
n_{\text {drum }}=\frac{V_{\text {rope }}}{D_{\text {drum } x \pi}}
$$

$\mathrm{V}_{\text {rope }}=$ kecepatan linier pada sling $(\mathrm{m} / \mathrm{s})$

Setelah dilakukan perhitungan pada masing-masing komponen pengangkat, kemudian dilakukan perbandingan desain lama dengan desain baru, untuk diketahui perbedaannya.

\section{HASIL DAN ANALISIS}

Berdasarkan spesifikasi tower crane Potain MD 900, dibuat grafik kebutuhan daya angkat tower crane terhadap kecepatan dan grafik rasio gearbox terhadap kecepatan, dengan perhitungan statis maupun dinamis. 


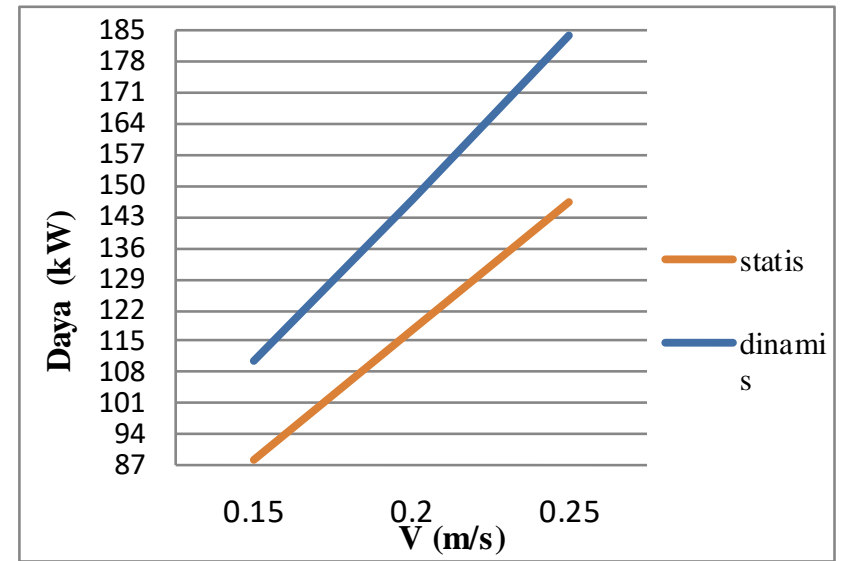

Gambar 3. Grafik Kebutuhan DayaMotor Tower Crane pada Kapasitas 50 Ton dan Rope Reeving 2.

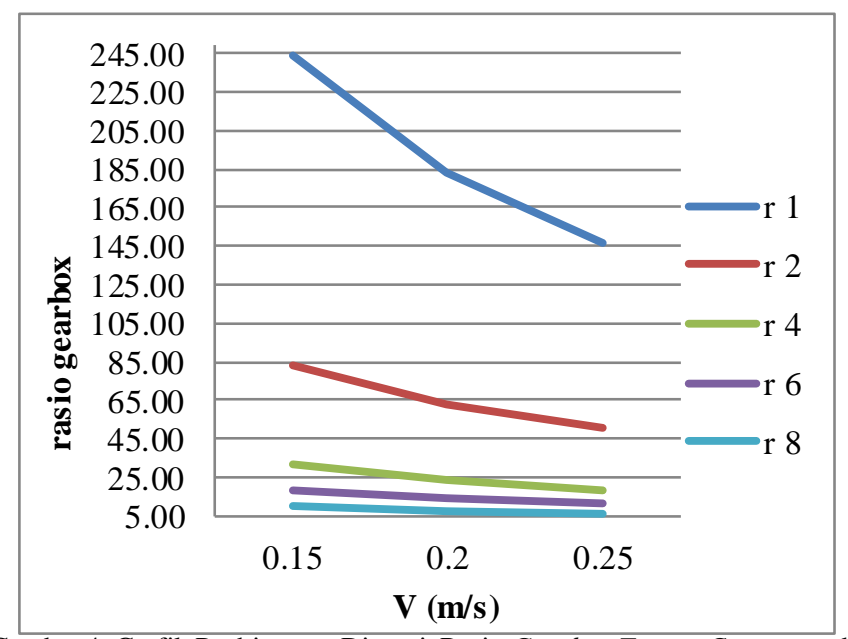

Gambar 4. Grafik Perhitungan Dinamis Rasio Gearbox Tower Crane pada Kapasitas 50 Ton dan Rope Reeving 2.

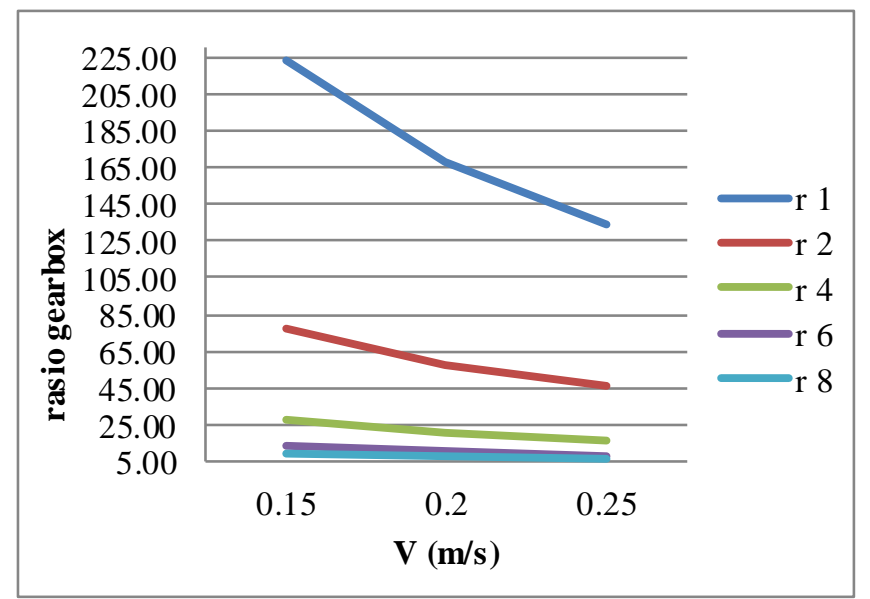

Gambar 5. Grafik Perhitungan Statis Rasio Gearbox Tower Crane pada Kapasitas 50 Ton dan Rope Reeving 2.

\section{A. Perhitungan Kebutuhan Daya Motor Tower Crane pada Kapasitas 50 Ton dan Rope Reeving 2}

Berdasarkan persamaan (1), (2) dan (8), maka didapatkan grafik daya motor tower crane dengan perhitungan statis dan dinamis pada kapasitas angkat 50 ton, seperti pada gambar 3 . Grafik pada gambar 3 menunjukkan bahwa pada perhitungan dinamis nilai kebutuhan daya motor lebih besar bila dibandingkan dengan perhitungan statis.

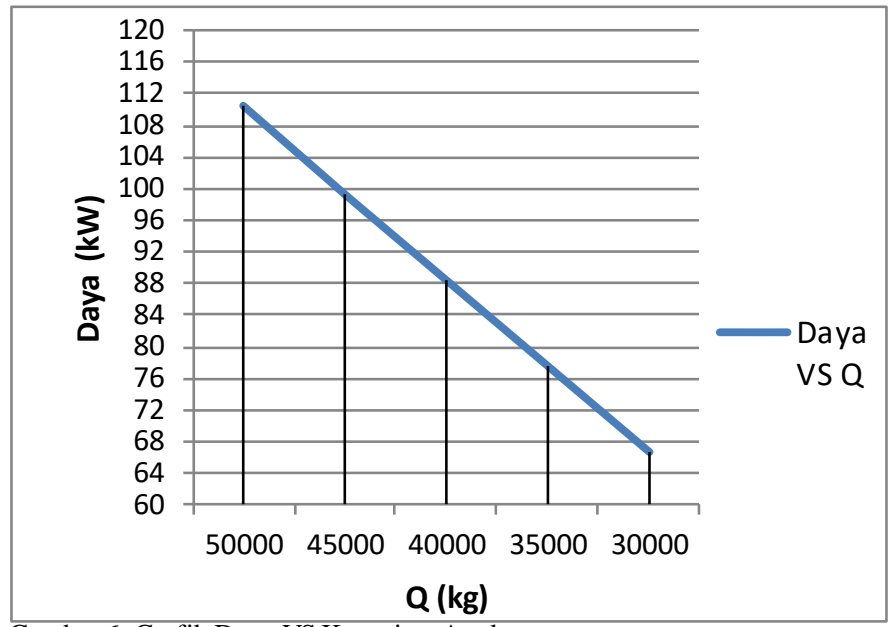

Gambar 6. Grafik Daya VS Kapasitas Angkat.

B. Perhitungan Rasio Gearbox Tower Crane pada Kapasitas 50 Ton dan Rope Reeving 2

Berdasarkan spesifikasi motor pada putaran $1000 \mathrm{rpm}$, dengan persamaan (9) dan (13), maka didapatkan grafik rasio gearbox tower crane dengan perhitungan dinamis dan statis pada kapasitas angkat 50 ton, seperti yang ditunjukkan pada gambar 4 dan 5. Pada grafik 4 dan 5 terlihat bahwa semakin besar jumlah rope reeving dan kecepatan angkat maka nilai rasio gearbox semakin kecil, begitu pula sebaliknya. Pada variasi kecepatan angkat yang sama pada gambar 5 terlihat nilai rasio gearbox nya lebih kecil bila dibandingkan dengan pada gambar 4.

\section{Analisis Kemampuan Angkat Tower Crane}

Dengan melakukan perhitungan dinamis seperti pada persamaan (2) dan (8) pada kecepatan angkat $0.15 \mathrm{~m} / \mathrm{s}$ dan rope reeving 2 maka didapatkan grafik kebutuhan daya motor terhadap variasi beban angkat, seperti yang ditunjukkan pada gambar 6. Berdasarkan grafik yang ditunjukkan pada gambar 6 dengan daya motor sebesar $88 \mathrm{~kW}$ tower crane hanya mampu mengangkut kapasitas sebesar 40 ton dan hal ini sesuai dengan kasus pada PT Dok Surabaya. Oleh karena itu untuk menentukkan daya motor berdasarkan kapasitas angkat perlu dilakukan perhitungan dinamis begitu pun dalam melakukan redesign untuk menaikkan kapasitas angkat, sehingga tidak hanya beban angkat yang diperhitungkan namun berat hook block pulley, angka SWL dan juga percepatan yang terjadi perlu diperhitungkan pula.

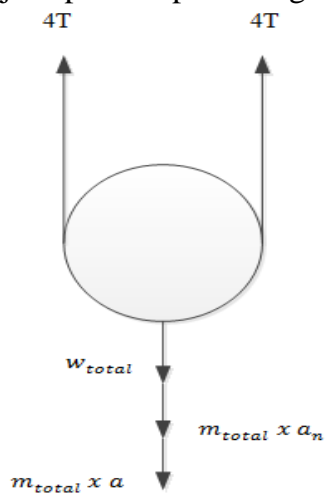

Gambar 7. Gaya-Gaya yang Bekerja pada Tower Crane Ketika Hoisting. 


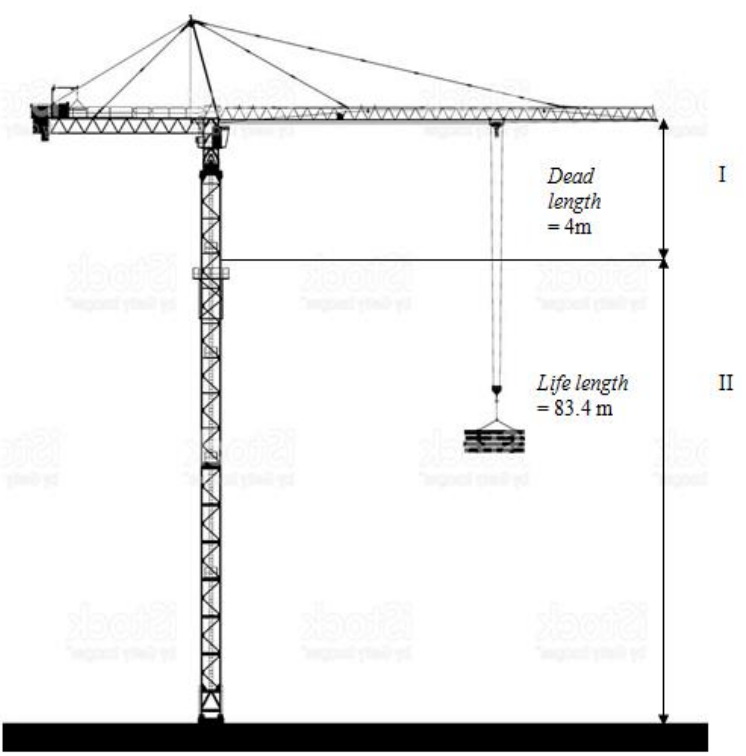

Gambar 8. Dead Length dan Life Length pada Tower Crane.

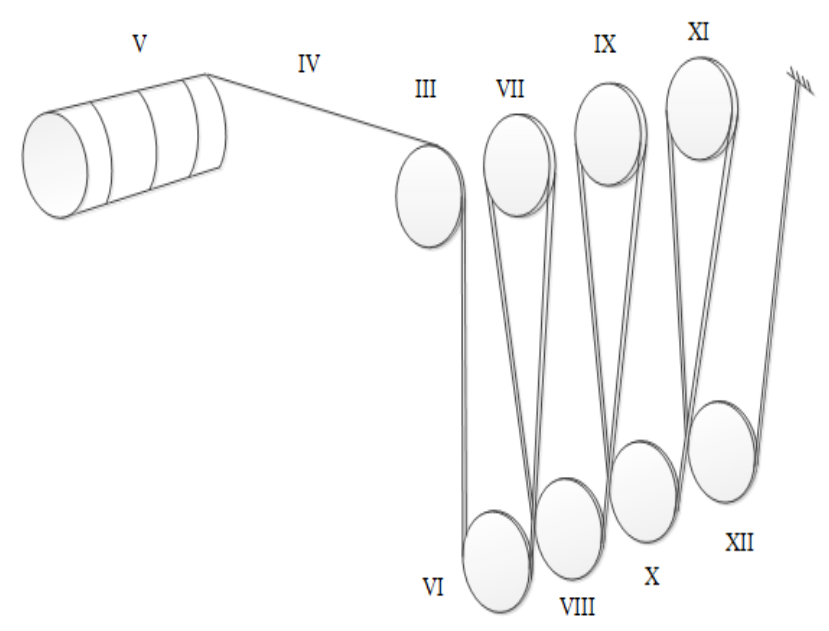

Gambar 9. Skema Wire Rope dengan Rope Reeving 8/1.

D. Pemilihan Tali Baja (Wire Rope) Hasil Redesign pada Kapasitas Angkat 50 Ton, Rope Reeving 8 dan Kecepatan Angkat $0.15 \mathrm{~m} / \mathrm{s}$

Berdasarkan spesifikasi tower crane, dilakukan perhitungan dengan menggunakan persamaan (4) dan diperoleh nilai dari percepatan linier (a) yaitu $0.003 \mathrm{~m} / \mathrm{s}^{2}$, dari nilai ini kemudian dapat digunakan untuk mengetahui besarnya gaya angkat yang dapat dihitung menggunakan persamaan (3).

Setelah itu dilakukan perhitungan untuk mencari jarak yang ditempuh oleh beban secara vertikal hingga mencapai kondisi sesaat sebelum konstan dengan menggunakan persamaan (7) dan didapat nilai sebesar $3.625 \mathrm{~m}$, berdasarkan nilai ini dapat diketahui panjang tali ketika mengayun yaitu sebesar $79.7 \mathrm{~m}$. Setelah itu dari nilai panjang tali ketika mengayun kemudian dapat diketahui nilai percepatan normal menggunakan persamaan (6) sebesar $0.0004 \mathrm{~m} / \mathrm{s}^{2}$. Dari nilai percepatan normal ini kemudian dapat dihitung nilai dari gaya ayun menggunakan persamaan (5).

Setelah didapat nilai dari percepatan linier maupun percepatan normal, maka dapat dihitung gaya tegang yang diterima tali berdasarkan free body diagram dan persamaan (2), maka didapatkan gaya tegang tali (T) sebesar $77279.60 \mathrm{~N}$. Berdasarkan nilai gaya tegang maka didapatkan nilai diameter tali sebesar $12 \mathrm{~mm}$.

E. Perhitungan Pulley Hasil Redesign pada Kapasitas Angkat 50 Ton, Rope Reeving 8 dan Kecepatan Angkat 0.15 $\mathrm{m} / \mathrm{s}$

Diameter pulley dapat ditentukan berdasarkan persamaan (10) dan didapat nilai sebesar $270 \mathrm{~mm}$.

F. Perhitungan Drum Hasil Redesign pada Kapasitas Angkat 50 Ton, Rope Reeving 8 dan Kecepatan Angkat $0.15 \mathrm{~m} / \mathrm{s}$

Diameter drum ditentukan berdasarkan persamaan (11) dan didapatkan nilai sebesar $240 \mathrm{~mm}$. Sedangkan untuk menentukan diameter drum flange $\left(\mathrm{D}_{2}\right)$ digunakan persamaan (12) dan didapatkan nilai sebesar $381 \mathrm{~mm}$. Sedangkan untuk menghitung panjang tali yang dibutuhkan pada rope reeving 8 , mengacu pada gambar 8 dan 9 adalah sebagaiberikut :

\begin{tabular}{lll} 
I & $4000 \mathrm{~mm} \times 8 \mathrm{fall}$ & $=32000 \mathrm{~mm}$ \\
II & $83400 \mathrm{~mm} \times 8 \mathrm{fall}$ & $=667200 \mathrm{~mm}$ \\
III & $\frac{1}{4} \times \pi \times 270 \mathrm{~mm}$ & $=212 \mathrm{~mm}$ \\
IV & sesuai skema & $=60000 \mathrm{~mm}$ \\
V & 10 lilitan $\times \pi \times 240 \mathrm{~mm}$ & $=7536 \mathrm{~mm}$ \\
VI & $\frac{1}{2} \times \pi \times 270 \mathrm{~mm}$ & $=424 \mathrm{~mm}$ \\
VII & $\frac{1}{2} \times \pi \times 270 \mathrm{~mm}$ & $=424 \mathrm{~mm}$ \\
VIII & $\frac{1}{2} \times \pi \times 270 \mathrm{~mm}$ & $=424 \mathrm{~mm}$ \\
IX & $\frac{1}{2} \times \pi \times 270 \mathrm{~mm}$ & $=424 \mathrm{~mm}$ \\
X & $\frac{1}{2} \times \pi \times 270 \mathrm{~mm}$ & $=424 \mathrm{~mm}$ \\
XI & $\frac{1}{2} \times \pi \times 270 \mathrm{~mm}$ & $=424 \mathrm{~mm}$ \\
XII & $\frac{1}{2} \times \pi \times 270 \mathrm{~mm}$ & $=424 \mathrm{~mm}$ \\
\hline Total & & $=769916 \mathrm{~mm} \approx 770 \mathrm{~m}$
\end{tabular}

Tabel 3 .

Perbandingan Desain Lama dengan Hasil Redesign

\begin{tabular}{|l|c|c|c|c|c|}
\hline & $\begin{array}{c}\text { Desain } \\
\text { lama }\end{array}$ & \multicolumn{4}{|c|}{ Hasil Redesign } \\
\hline Rope reeving & 2 & 2 & 4 & 6 & 8 \\
\hline Kapasitas angkat & 40000 & 50000 & 50000 & 50000 & 50000 \\
\hline Daya motor & $88 \mathrm{~kW}$ & $110 \mathrm{~kW}$ & $110 \mathrm{~kW}$ & $110 \mathrm{~kW}$ & $110 \mathrm{~kW}$ \\
\hline Diameter tali & $22 \mathrm{~mm}$ & $24 \mathrm{~mm}$ & $18 \mathrm{~mm}$ & $16 \mathrm{~mm}$ & $12 \mathrm{~mm}$ \\
\hline Diameter drum & $440 \mathrm{~mm}$ & $480 \mathrm{~mm}$ & $360 \mathrm{~mm}$ & $320 \mathrm{~mm}$ & $240 \mathrm{~mm}$ \\
\hline $\begin{array}{l}\text { Putaran drum } \\
\text { rpm }\end{array}$ & 13.03 & $11.94 \mathrm{rm}$ & $31.85 \mathrm{rm}$ & $53.73 \mathrm{rm}$ & $95.54 \mathrm{rmm}$ \\
\hline Rasio Gearbox & 76.76 & 83.73 & 31.4 & 18.61 & 10.47 \\
\hline $\begin{array}{l}\text { Effisiensi } \\
\text { Gearbox dengan } \\
\text { parallel shaft } \\
\text { gear }\end{array}$ & 0.86 & 0.86 & 0.86 & 0.86 & 0.9 \\
\hline Jumlah pulley & 2 & 2 & 4 & 6 & 8 \\
\hline Panjang sling & $238 \mathrm{~m}$ & $238 \mathrm{~m}$ & $416 \mathrm{~m}$ & $593 \mathrm{~m}$ & $770 \mathrm{~m}$ \\
\hline lebar drum & $356 \mathrm{~m}$ & $356 \mathrm{~m}$ & $356 \mathrm{~m}$ & $356 \mathrm{~m}$ & $248 \mathrm{~m}$ \\
\hline Diameter flange & $762 \mathrm{~mm}$ & $914 \mathrm{~mm}$ & $610 \mathrm{~mm}$ & $610 \mathrm{~mm}$ & $381 \mathrm{~mm}$ \\
\hline
\end{tabular}


Tabel 4.

Evaluasi Hasil Redesign Tower Crane Potain MD 900

\begin{tabular}{|c|c|c|c|c|}
\hline & \multicolumn{4}{|c|}{ Hasil Redesign } \\
\hline Rope reeving & 2 & 4 & 6 & 8 \\
\hline Diameter tali & Buruk & Cukup & Baik & Sangat Baik \\
\hline Diameter drum & Buruk & Cukup & Baik & Sangat Baik \\
\hline Putaran drum & Buruk & Cukup & Baik & Sangat Baik \\
\hline Rasio Gearbox & Buruk & Cukup & Baik & Sangat Baik \\
\hline $\begin{array}{ll}\text { Effisiensi } & \text { Gearbox } \\
\text { dengan } & \text { parallel } \\
\text { shaft gear } & \\
\end{array}$ & Baik & Baik & Baik & Sangat Baik \\
\hline Jumlah pulley & Sangat Baik & Baik & Cukup & Buruk \\
\hline Panjang sling & Sangat Baik & Baik & Cukup & Buruk \\
\hline lebar drum & Baik & Baik & Baik & Sangat Baik \\
\hline Diameter flange & Buruk & Cukup & Cukup & Baik \\
\hline
\end{tabular}

Keterangan tabel 4

Buruk : : 0-40

Cukup $\quad: 41-60$

Baik : :61-80

Sangat Baik : 81-100

G. Pemilihan Motor Hasil Redesign pada Kapasitas Angkat 50 Ton, Rope Reeving 8 dan Kecepatan Angkat $0.15 \mathrm{~m} / \mathrm{s}$

Dalam menentukan daya motor hasil redesign digunakan persamaan (2) dan (8) dan didapatkan nilai sebesar $110 \mathrm{~kW}$.

H. Pemilihan Gearbox Hasil Redesign pada Kapasitas Angkat 50 Ton, Rope Reeving 8 dan Kecepatan Angkat 0.15 $\mathrm{m} / \mathrm{s}$

Dengan nilai drum yang sudah didapatkan pada perhitungan sebelumnya yaitu sebesar $240 \mathrm{~mm}$ dan jumlah rope reeving 8/1 maka nilai putaran drum dapat dicari menggunakan persamaan (13) sehingga didapatkan nilai putaran drum sebesar $95.54 \mathrm{rpm}$.

Setelah didapatkan nilai putaran drum maka selanjutnya dapat dicari nilai rasio pada gearbox menggunakan persamaan (9) dan didapatkan nilai rasio sebesar 10.47.

\section{Perbandingan Desain Lama VS Hasil Redesign}

Dari tabel 3 dapat dilihat dengan menggunakan perhitungan dinamis untuk menaikkan kapasitas angkat menjadi 50 ton dibutuhkan daya motor yang lebih besar dari desain lama yaitu
$88 \mathrm{~kW}$. Untuk nilai rasio gearbox pada desain lama adalah 76.76 ketika dilakukan redesign dengan variasi rope reeving maka semakin besar nilai rope reeving maka akan semakin kecil rasio gearbox nya. Dengan nilai evaluasi seperti pada keterangan tabel 5, maka untuk hasil redesign dengan rope reeving 2 didapatkan hasil sebesar 58 sehingga masuk kategori cukup. Untuk hasil redesign dengan rope reeving 4 didapatkan hasil sebesar 68 sehingga masuk kategori cukup baik. Untuk hasil redesign dengan rope reeving 6 didapatkan hasil sebesar 73 sehingga masuk kategori cukup baik. Dan yang terakhir untuk hasil redesign dengan rope reeving 8 didapatkan hasil sebesar 84 sehingga masuk kategori sangat baik. Sehingga dapat disimpulkan hasil redesign dengan rope reeving 8 lebih baik bila dibandingkan dengan hasil redesign yang lain.

\section{KESIMPULAN/RINGKASAN}

Berdasarkan hasil perhitungan dan pengolahan data dari penelitian tower crane Potain MD 900 ini, tugas akhir ini dapat disimpulkan :

1. Hasil perhitungan daya motor dengan kapasitas angkat maksimum sebesar 50 ton pada perhitungan statis didapatkan daya sebesar $88 \mathrm{~kW}$ sedangkan pada perhitungan dinamis didapatkan daya sebesar $110 \mathrm{~kW}$

2. Rasio gearbox pada desain tower crane yang lama sebesar 76.76 sedangkan rasio gearbox hasil redesign didapat nilai sebesar 10.5

3. Pada desain lama dengan rope reeving 2/1 dan kapasitas 40 ton didapat daya motor $88 \mathrm{~kW}$ dan rasio gearbox sebesar 76.76 sedangkan pada hasil redesign dengan rope reeving 8/1 dan kapasitas 50 ton didapat daya motor $110 \mathrm{~kW}$ dan rasio gearbox sebesar 10.5.

\section{DAFTAR PUSTAKA}

[1] PT Dok dan Perkapalan, "Profil Perusahaan," 2011. [Online]. Available: http://www.dok-sby.id.

[2] A. Nurcahyo and C. Bintang, "Optimasi Penempatan Group Tower Crane pada Proyek Pembangunan My Tower Surabaya." 2017.

[3] R. Hibbeler, Engineering Mechanics Dynamics, 12th ed. 2010.

[4] C. D. Deut schman, Aaron. J. Michels, Walter. E. Wilson, Machine Design Theory and Practice. United State of America, 1975.

[5] N. Rudenko, Mesin Pengangkat. Jakarta: Erlangga, 1996. 